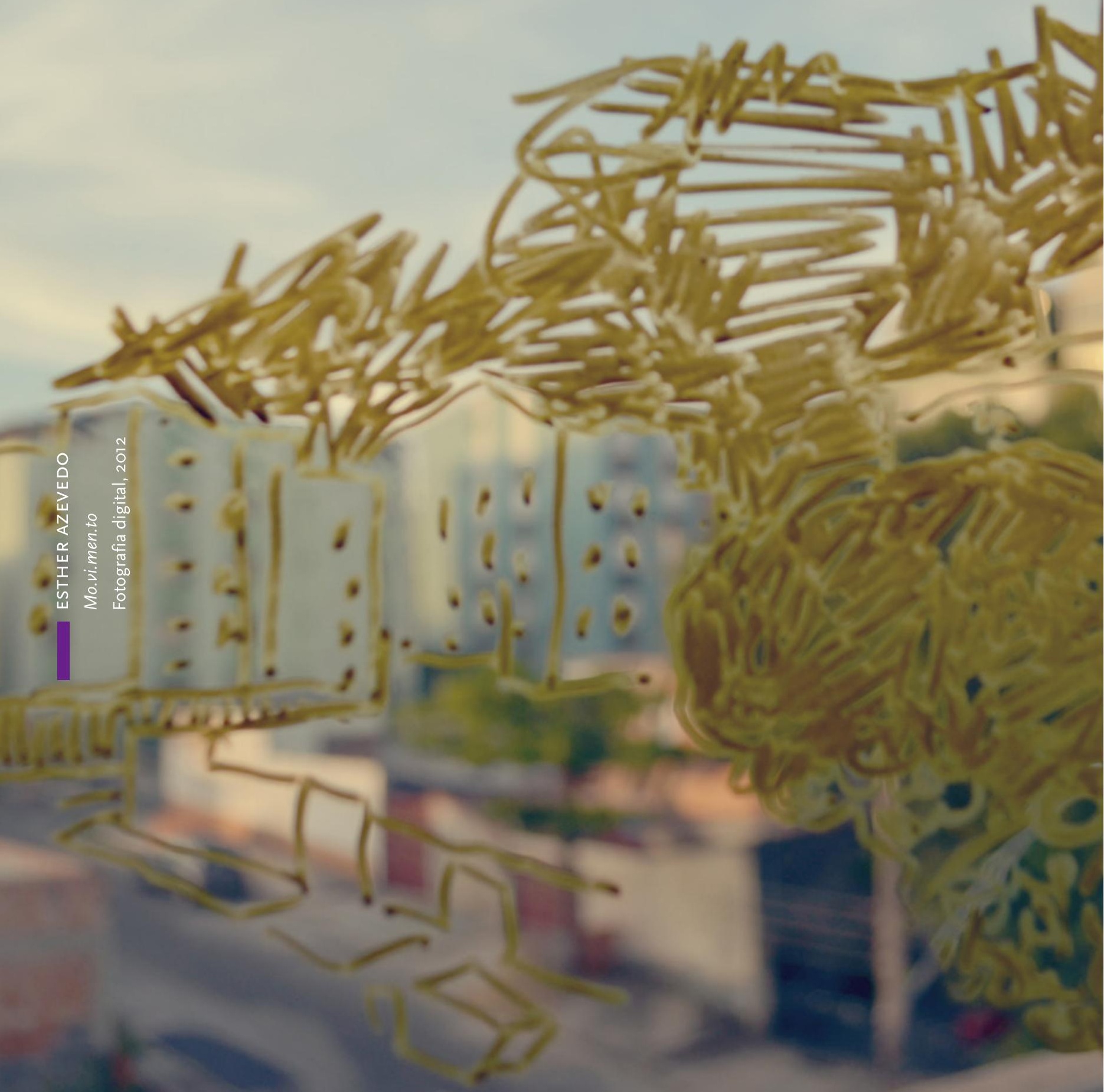




\section{APROXIMAÇÃO ENTRE TEORIA E PRÁTICA URBANA:} reflexões a partir do pensamento de Henri Lefebure

\section{GERALDO MAGELA COSTA*}

RESU MO Procura-se neste ensaio discutir a análise dos processos socioespaciais urbanos por meio de uma reflexão sobre a relação entre teoria, realidade e possibilidade das práticas, entre elas a do planejamento urbano. Para isso, procura-se destacar passagens do pensamento de alguns autores sobre a questão, em especial Henri Lefebvre. As reflexões são desenvolvidas utilizando-se um recurso analítico que procura entender dois momentos de aproximação: um primeiro entre o pensamento filosófico e teórico e a realidade e, um segundo, entre este mundo real e a possibilidade da prática emancipatória. Para refletir sobre esta segunda aproximação, introduz-se, além da contribuição teórica de alguns autores, o relato de uma experiência recente de planejamento urbano/metropolitano realizada no âmbito da Universidade Federal de Minas Gerais, por meio da elaboração do Plano Diretor de Desenvolvimento Integrado para a Região Metropolitana de Belo Horizonte.

PALAVRAS-ChAVE Teoria urbana. Prática urbana. Henri Lefebvre.

\section{APROACHING URBAN THEORY AND PRACTICE:}

\section{reflections upon Henri Lefebure's thinking}

ABSTRACT This essay discusses the analysis of the urban socio-spatial processes approaching the relationship between theory, reality and possibility of practices, including urban planning, supported by some authors' thoughts on the subject, particularly Henri Lefebvre. The reflections are developed by means of an analytical framework that seeks to understand two approaches: between the philosophical and theoretical thought and reality, and between the real world and the possibility of the emancipatory practice. To reflect on this second approach, besides the theoretical contribution of some authors, a recent experience of urban/metropolitan planning is introduced, carried out by the Federal University of Minas Gerais through the elaboration of the Integrated Development Master Plan for the Metropolitan Region of Belo Horizonte.

KEYWORDS Urban theory. Urban practice. Henri Lefebvre.

* Professor Associado do Departamento de Geografia do Instituto de Geociências da Universidade Federal de Minas Gerais - UFMG (Brasil).E-mail: <gemcosta.bhz@terra.com.br>. 
pensamento de Henri Lefebvre tem sido motivo de debates e controvérsias, especialmente em torno dos conceitos de urbano, cidade e espaço. Se por um lado isso tem levado, talvez em razão de leituras superficiais ou equivocadas, a questionamentos sobre o pensamento livre desse filósofo, por outro em resultado em efeitos positivos, uma vez que colocam em evidência, de forma cada vez mais intensa, a sua contribuição para o pensamento crítico sobre a sociedade e suas transformações. Uma “cobrança”, relacionada ao entendimento de seu pensamento refere-se à relação entre teoria e prática. Harvey (2009) assim escreve sobre essa questão:

Ele [Lefebvre] elabora uma devastadora crítica de concepções cartesianas, do absolutismo político que advém de concepções absolutas do espaço, das opressões que se abatem sobre o mundo devido a uma espacialidade racionalizada, burocratizada, definida tecnocrática e capitalisticamente. Para ele, a produção do espaço tem de permanecer uma possibilidade interminavelmente aberta. O efeito, infelizmente, é deixar frustrantemente indefinidos os espaços reais de alguma alternativa. Lefebvre se recusa a fazer recomendações específicas. [...] Recusa-se a enfrentar o problema de base: o fato de que materializar o espaço é comprometer-se com o fechamento (ainda que de modo temporário), o que constitui um ato autoritário. [...] Se, por conseguinte, se deseja pôr alternativas em prática, não se pode fugir eternamente do problema do fechamento (e do autoritarismo que ele pressupõe). (HARVEY, 2009, p. 304)

Haveria de fato uma recusa de Lefebvre em enfrentar o problema que, segundo Harvey, implicaria um fechamento, um autoritarismo? Haveria na vasta produção de Lefebvre e de lefebvrianos uma teoria sobre a cidade ou o urbano (teoria urbana)? O que é a cidade quando Lefebvre nos fala do direito a ela? É real, concreta? Ou é uma virtualidade, sinônimo de urbano? Havendo ou não uma teoria da cidade (teoria urbana), o pensamento de Lefebvre traz contribuições importantes para uma aproximação com a prática urbana? O uso das suas reflexões teóricas para a análise e o planejamento urbanos significa redução de seu pensamento? Reflexões sobre 


\section{O direito à cidade práticas concretas - heterônomas e autônomas} é em essência

- poderiam contribuir para avaliar a contribuição de Lefebvre e de pensadores lefebvrianos para a aprouma ideia que ximação entre teoria e prática? Por fim, uma pergunnos move na ta provocativa: Precisamos de mais (novas?) reflexões construção teórica do urbano hoje teóricas para a realização de uma aproximação com a prática? Qual teoria? Qual prática? Propõe-se como objetivo neste ensaio reunir e ainda virtual, da discutir reflexões críticas sobre algumas das quessociedade urbana

tões aqui colocadas, que têm sido recorrentes no processo de pensar o urbano e a cidade no Brasil e, acredito, em outros países da América Latina. Metodologicamente, pretende-se desenvolver as reflexões propostas neste ensaio a partir da contribuição de Lefebvre, de outros autores críticos e/ou identificados com seu pensamento, e de observações sobre a prática do planejamento e da gestão urbana em Belo Horizonte e sua região metropolitana.

$O$ direito à cidade tem inspirado muitos de nós em nossas tentativas de contribuirmos para pensar formas de mudança social. Desta perspectiva, o direito à cidade é em essência uma ideia que nos move na construção teórica do urbano hoje ainda virtual, da sociedade urbana (LEFEBVRE, 1999, 2008). Para isso toda essa construção está carregada de uma necessária abstração. Com isso, concordamos que a principal contribuição de Lefebvre é teórica. Isso está presente em suas reflexões sobre o urbano, a sociedade urbana, o espaço diferencial e a necessidade da prática (práxis) socioespacial como forma de realização da sociedade urbana (LEFEBVRE, I993, 1999). Entendo que "o direito à cidade" em Lefebvre pode ser interpretado como uma ideia iluminadora que nos guia no processo de pensar a possibilidade dessa realização. Em A revolução urbana, Lefebvre assim se refere ao conceito de sociedade urbana: "Trata-se de uma hipótese teórica que o pensamento científico tem o direito de formular e de tomar como ponto de partida. Tal procedimento não só é 
1. A separação em duas

fases de aproximação na FIG.1 é um recurso analítico apenas, uma vez que, em termos lefebvrianos, a práxis é indissociável da teoria no processo de pensar a realização da sociedade urbana.

A construção da primeira coluna foi inspirada em uma apresentação de Ed Soja no Encontro de Geógrafos da América Latina (EGAL), Buenos Aires, 1999. A sequência

do topo para a base nesta coluna não sugere um roteiro metodológico a ser seguido.

Tanto a reflexão teórica (no topo) quanto a análise empírica (na base), podem

por elas mesmas trazer contribuições para a aproximação com o "real". Deve-se ainda observar que certas reflexões teóricas, como as de Lefebvre sobre a sociedade urbana, não permitem uma direta e decorrente formulação de categorias de análise empírica. corrente nas ciências sociais, como necessário. Não há ciência sem hipóteses teóricas" (1999, p. I6, destaque no original).

Parece correto considerar, como o fazem alguns intérpretes do pensamento de Lefebvre, que qualquer tentativa de transformar a ideia de direito à cidade em categoria de análise empírica ou em um guia para políticas públicas, ou ainda de considerá-la somente enfatizando o caráter jurídico-legal do direito, por exemplo, pode ser interpretada como uma visão estreita ou equivocada da teoria, especialmente quando se concorda que a ideia do direito à cidade é parte do processo de aproximação com a virtualidade inerente ao conceito de urbano e de sociedade urbana (LEFEBVRE, I999). Há certamente riscos de reificação de conceitos e de princípios teóricos nessa tentativa de aproximação. No entanto, pensar a possibilidade de transformação social requer, com os devidos cuidados, correr os riscos inerentes a um modo de pensar que reconheça a indissociabilidade entre teoria e prática.

A esse respeito, Lefebvre (I999, p. I8, destaques no original) diz que "A expressão ‘sociedade urbana' responde a uma necessidade teórica”. A indissociabilidade acima referida é colocada logo a seguir pelo autor: “Um movimento do pensamento em direção a um certo concreto e talvez para o concreto se esboça e se precisa. Esse movimento, caso se confirme, conduzirá a uma prática, a prática urbana, apreendida ou re-apreendida”. Enfim, qualquer movimento em direção à busca de alternativas que levem a mudanças socioespaciais efetivas significa a necessidade da aproximação entre teoria e práxis, o que está na essência do pensamento de Lefebvre sobre o urbano.

Portanto, a pergunta acima formulada sobre uma possível recusa de Lefebvre em enfrentar o problema do fechamento, da materialização do espaço, pode agora ser problematizada. Em primeiro lugar devemos questionar o que Harvey quer dizer com “materializar o espaço”. No meu entendimento, com esta expressão o autor está se referindo às difíceis passagens: primeiro, do pensamento filosófico para a construção de teorias de aproximação com o real; e, segundo, de construir formas de "pôr alternativas em prática” (HARVEY, 2009) que, no caso da produção do espaço, significa entrar na arena dos movimentos sociais, autônomos ou heterônomos, na natureza e no papel do Estado e, no caso deste ensaio, na possibilidade de o pensamento e reflexões construídos no âmbito da universidade contribuírem como prática no sentido aqui discutido (FIG. I) ${ }^{\mathrm{I}}$. 


$$
\text { 1a APROXIMAÇÃO }
$$

1- Avanços no conhecimento (inclusive teórico)

2- Aproximação com o "real"

3- Possibilidades de mudança social

\section{2a APROXIMAÇÃO}
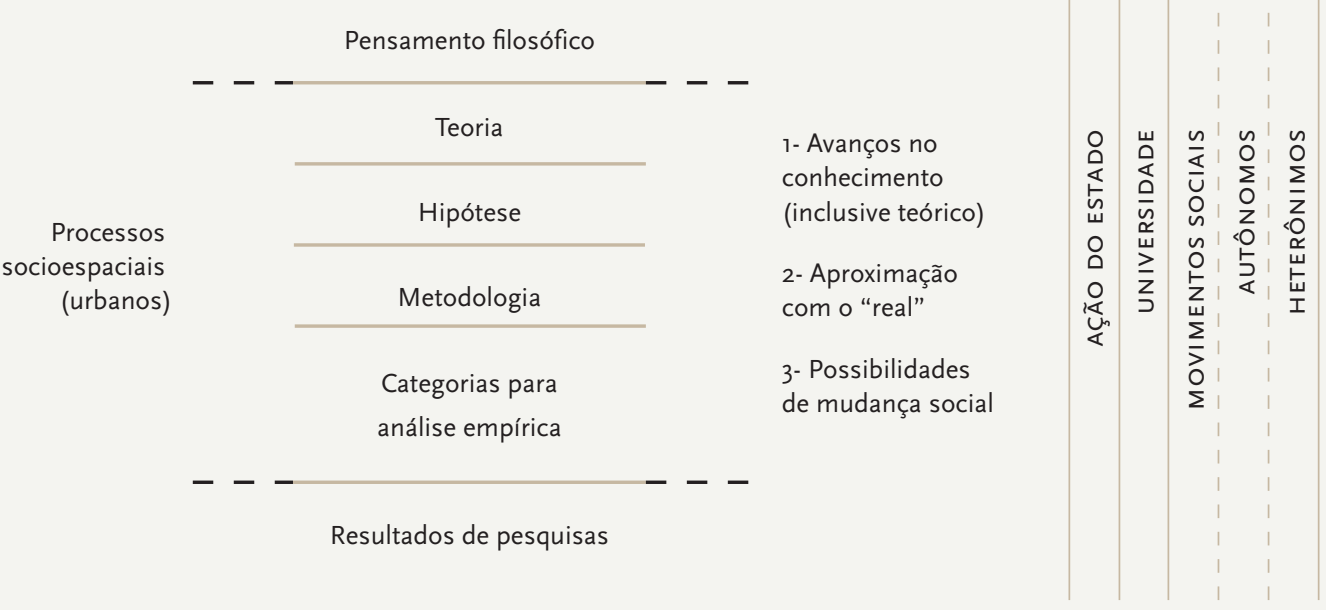

Mudança social?

Reforma?

Ou o quê?

FIGURA I

Não é minha intenção neste ensaio avançar nesta discussão em toda a sua totalidade, mas formular outras perguntas que contribuam para a busca de uma aproximação com tal problemática. Por um lado, não há dúvidas sobre o risco de, nesse processo de "materializar o espaço", retornarmos aos princípios funcionalistas que ainda persistem, por exemplo, nas atividades de planejamento de base territorial, que requerem leituras, mapeamentos e zoneamentos, além da questão da linguagem que os permeia, para, por exemplo, informar o estabelecimento de instrumentos de regulação do parcelamento, da ocupação e do uso do solo.

Por outro lado, no entanto, refletir sobre a possibilidade da sociedade urbana e enfatizar a necessidade da práxis socioespacial para torná-la possível, como o faz Lefebvre em A revolução urbana, não seria um avanço muito importante que transcende o pensamento estrutural bastante generalizado e de viés econômico sobre os 
processos espaciais? Penso que tal reflexão tem contribuído de forma efetiva, sem risco de reificação de conceitos, para avançar na ou iluminar a construção de alternativas que possam ser postas em prática.

Em segundo lugar, vale a pena "ouvir" a resposta de Lefebvre quando foi perguntado sobre a questão aqui discutida em entrevista publicada em I 99०:

Entrevistador: Não acha que a ação implica uma opção reduzida? Não existem duas lógicas, a do cidadão Lefebvre e a do filósofo Lefebvre?

H. Lefebvre: É uma questão que não tem resposta porque eu não tenho experiência. Nunca tive influência direta. Tive indireta, mas só como subproduto. Admito que se me fosse dada a responsabilidade - e gostaria de pensar nisso antes de aceitar -, poderia ver elementos básicos dos problemas, as formas e o espaço. Talvez depois de um longo e ponderado exame aceitaria, mas não com certeza, pois é uma enorme responsabilidade. (LEFEBVRE, I990, p. 67)

Entendo que essa resposta não traduz uma recusa em "materializar o espaço". Trata-se de uma reflexão sincera sobre as possibilidades e as dificuldades relacionadas à aproximação com a "experiência direta”. O fato de "ver elementos básicos dos problemas, as formas e o espaço", não seria uma evidência da possibilidade de aproximação entre o filósofo e o cidadão?

A indissociabilidade entre teoria e prática está certamente também presente quando Lefebvre (I999, I993) introduz outro conceito central - o de espaço diferencial - na construção de suas reflexões sobre possibilidades de emancipação. Trata-se de um conceito que, em sua essência, tem o mesmo significado de urbano ou de sociedade urbana. Já em A revolução urbana, na excelente reflexão sobre "o campo cego" da passagem do industrial para o urbano, como parte do eixo espaço-

2. Campo cego, branco, vazio, fase crítica, caixa preta são termos usados pelo autor para identificar o que caracteriza a problemática urbana na passagem do industrial para o urbano. temporal, ${ }^{2}$ Lefebvre (I999), escreve:

O espaço-tempo urbano, desde que não seja mais definido pela racionalidade industrial - por seu projeto de homogeneidade -, aparece como diferencial: cada lugar e cada momento não tendo existência senão num conjunto, pelos contrastes e oposições que o vinculam aos outros lugares e momentos, distinguindo-o. (LEFEBVRE, I999, p. 45, destaque no original).

Mais tarde, em A produção do espaço, o conceito de espaço diferencial torna-se mais bem elaborado e preciso. Na construção do conceito, Lefebvre (I993, p. 48, destaques no 
original) começa pelo espaço absoluto, ainda não capitalista: “religioso e político em caráter, foi um produto com vínculos de consanguinidade, terra e linguagem, mas dele desenvolveu-se um espaço que foi relativizado e histórico". Com o advento do modo de produção capitalista esse panorama muda. Nas palavras do autor,

Foi durante este tempo que a atividade produtiva (trabalho) deixa de ser parte integrante do processo de reprodução que perpetuava a vida social; mas, ao tornar-se independente daquele processo, o trabalho torna-se presa da abstração, donde trabalho social abstrato - e espaço abstrato. (LEFEBVRE, I993, p. 49, destaque no original)

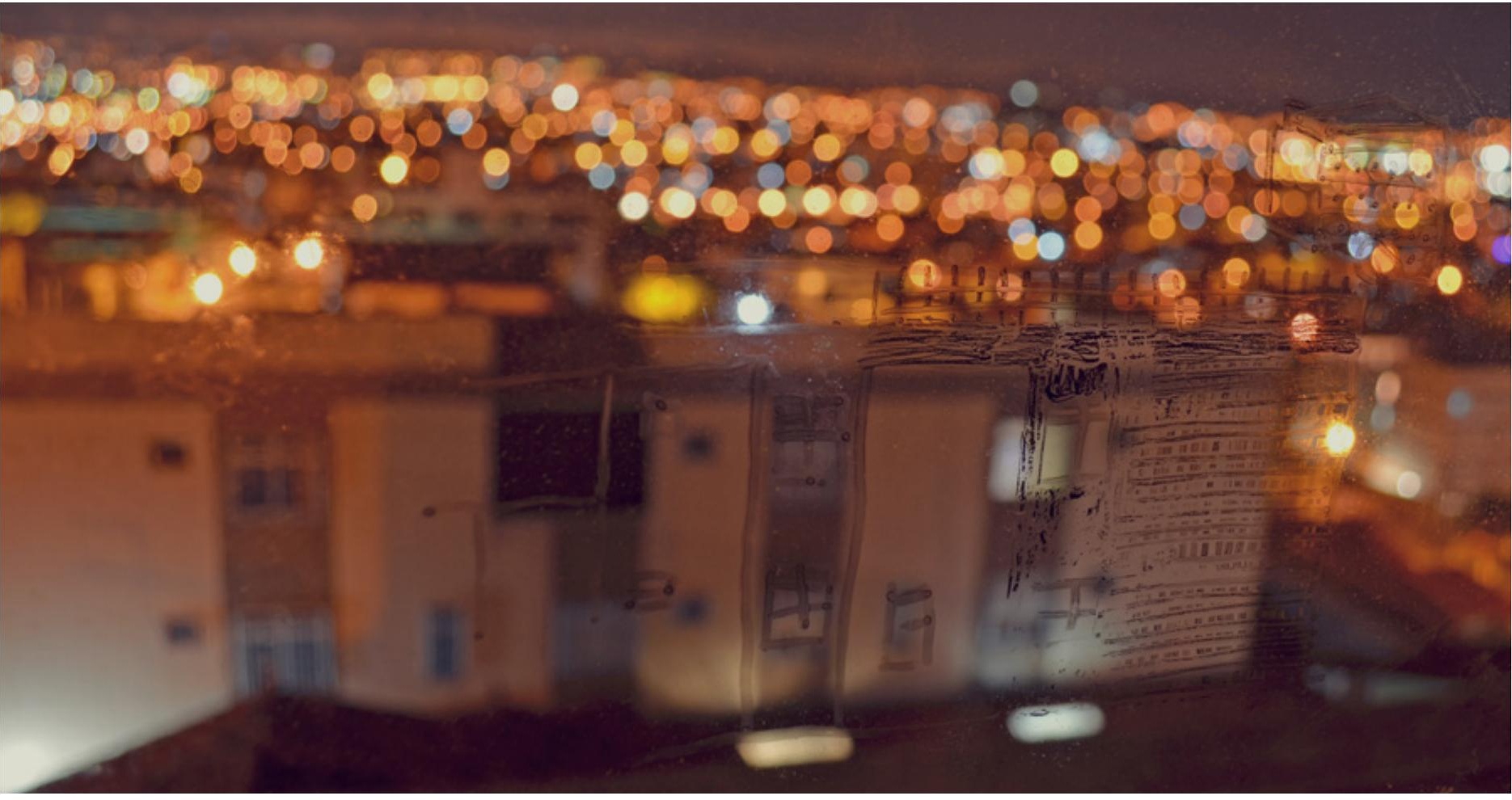

Sendo um espaço capitalista, nele se desenvolvem novas contradições que são inerentes ao modo de produção capitalista. Esse espaço abstrato atende, portanto, às necessidades de produção e de reprodução do capital. As contradições se expressam na forma em que ele se materializa: trata-se de um espaço ao mesmo tempo homogêneo - naquilo que se refere às condições gerais para a produção e a reprodução do capital - e fragmentado - uma vez que a produção do espaço abstrato é seletiva, o que resulta em exclusão socioespacial. 
Becker (I99I), apesar de não nominar explicitamente o espaço abstrato, identifica muito bem essas contradições, a ele inerentes, no processo de sua produção pelo Estado no contexto da modernização conservadora no Brasil, que teve seu auge no período do II Plano Nacional de Desenvolvimento (I975-1979). Segundo a autora, ao final deste período em que o país "alcançou o posição de oitavo PIB do mundo", pode-se observar que:

A modernização conservadora criou um espaço tecnicamente homogeneizado - facilitando a integração de lugares e tempos - mas também um espaço fragmentado porque a apropriação do território e a alocação de recursos foi fortemente seletiva, resultando em conflitos que se constituíram em embriões de novas territorialidades. (BECKER, I99I, p. 50)

Este espaço tecnicamente homogeneizado, o espaço abstrato, constituiu-se em elemento-chave da estratégia adotada pelo regime militar no processo de suporte à modernização da economia e à tentativa de integração do território, estendendo as condições gerais de produção e de reprodução do capital a todo o território nacional. No entanto, como a autora diz, os investimentos foram seletivos, o que resultou no ressurgimento e agravamento de conflitos socioterritoriais. Assim, a crise da modernização conservadora que se instala em fins dos anos I970 traduz-se também em crise do e no território. "A crise se manifesta em diferentes escalas. No nível local, na luta pelo direito ao lugar; ao nível regional no conflito para a preservação de domínios [dos segmentos capitalistas e grandes latifúndios favorecidos pela estratégia] e ao nível nacional na disputa pelo controle do mercado na semiperiferia” (BECKER, I99I, p. 5I).

Tais conflitos levaram ao que a autora denomina "embriões de novas territorialidades", resultado da crise do Estado militar autoritário em todas as suas dimensões: econômica, financeira, institucional, política, cultural. Pelo lado dos excluídos dos benefícios da estratégia, novos ou antigos movimentos sociais sufocados no período militar começam a tomar a forma de luta político-social na fase da democratização do país a partir da primeira metade dos anos I980. Não é meu propósito, neste ensaio, apresentar os desdobramentos desse processo de democratização que já foram amplamente identificados e analisados por vários autores, especialmente aqueles da

3. Ver entre outros Cardoso (1997), Maricato (1994, 1997), Souza (2003). escala local-urbana, relacionados aos movimentos sociais por uma reforma urbana. ${ }^{3}$ A intenção é retornar a Lefebvre começando por afirmar que essa análise de Becker constitui uma notável aproximação com o pensamento daquele autor. 
O espaço abstrato, espaço da acumulação e reprodução do capital abriga, segundo Lefebvre (I993, p. 49), "além de velhas contradições que permaneceram ao longo da história ou, principalmente, novas contradições relacionadas ao novo modo de produção". Essas contradições resultam em "confrontação entre espaço abstrato, ou a exteriorização de práticas econômicas e políticas que se originam com a classe capitalista $e$ com o estado, e espaço social, ou o espaço de valores de uso O espaço diferencial de produzidos pela complexa interação de todas as classes na vivência diária” (GOTTDIENER, I993, p. I3I). Referindo-se a esse espaço abstrato, Lefebvre (I979, p. 290) afirma que "nem o capitalismo nem o Estado pode manter o caótico, contraditório espaço que eles produziram". As reflexões desse autor sobre o acirramento dessas contradições e a decorrente explosão de espaços levam-no à construção Lefebvre é essencialmente uma virtualidade (ou uma utopia) que se encontra em processo de se tornar possível, dependendo da potência das lutas sociais, traduzidas em práxis do conceito de espaço diferencial, central para se avançar no processo de pensar a possibilidade da emancipação por meio da práxis espacial. Nas palavras do autor:

O espaço abstrato contém dentro de si mesmo as sementes de um novo tipo de espaço. Chamarei este novo espaço de 'espaço diferencial', porque, na medida em que espaço abstrato tende para a homogeneidade, para a eliminação de diferenças ou peculiaridades existentes, um novo espaço não pode nascer a não ser que ele acentue diferenças. (LEFEBVRE, I993, p. 52, destaque no original)

Deve-se ter cuidado para não confundir espaço diferencial, conforme conceituado por Lefebvre, com a diferença, especialmente cultural, de uso muito generalizado nas análises ditas pós-modernas. Não é que essas não sejam importantes. O que as diferencia é que o espaço diferencial em Lefebvre não é fenômeno dado, apenas histórica e naturalmente constituído. O espaço diferencial de Lefebvre é essencialmente uma virtualidade (ou uma utopia) que se encontra em processo de se tornar possível, dependendo da potência das lutas sociais, traduzidas em práxis espaciais. 

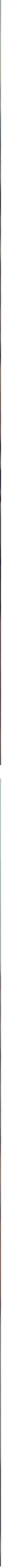
Com isso, para Lefebvre (I979), o espaço socialista será um espaço de diferenças.

Portanto, espaço diferencial e urbano são conceitos semelhantes em Lefebvre. Ambos apontam para a possível realização da sociedade urbana, mas pensada não apenas em termos conceituais e teóricos, uma vez que para tal realização os conceitos teóricos devem ser vistos de forma indissociável da práxis espacial, o que contém o germe da transformação emancipatória. No entanto, tal constatação não significa, naturalmente, que não há obstáculos para a efetiva realização dessa aproximação entre teoria e prática. Isso nos remete à última pergunta acima apresentada: Precisamos de mais (novas?) reflexões teóricas para a realização de uma aproximação com a prática? A continuidade de reflexão que esta pergunta suscita requer o seu desdobramento. A aproximação entre teoria e prática deve passar necessariamente por uma primeira fase de aproximação entre a teoria e o real? (FIG. I) Ou, a teoria crítica por si só já ilumina uma prática, que incluiria um aprendizado social, de aproximação com o real? Essas perguntas fazem sentido, uma vez que a aproximação com a realidade tem controvérsias. A percepção da realidade não seria diferenciada de acordo com as condições de classes sociais? Há também uma questão relacionada a "qual teoria" e "qual linguagem" seriam apropriadas para representar a realidade apreendida teoricamente. Ou seja, o espaço percebido não é difícil de ser verbalizado ou mapeado? Existe uma linguagem que dê conta disso?

Lefebvre reflete sobre isso quando discute "o campo cego". Ele se pergunta: "entre o industrial e o urbano, o que há?”, e responde:

Capas verbais, 'significantes flutuantes' soltos, cujo significado (a indústria, racionalidade e prática) não é mais suficiente, ainda que permaneça necessário. [...] Pode-se observá-las [as capas] como se contempla, do avião, as camadas e capas de nuvens. Eis aqui, muito alto, muito leves, os cirros da antiga filosofia. E os nimbos da racionalidade. E os pesados cúmulos dos cientificismos. Todos linguagens ou metalinguagens a meio caminho entre o real e o fictício, entre o realizado e o possível. (LEFEBVRE, I999, p. 37, destaque no original)

Com esse conjunto de metáforas Lefebvre nos coloca diante de um dilema: as “capas verbais" que são capazes de nos revelar o espaço industrial são insuficientes para desvendar o que se encontra dentro da "caixa preta". "Sabe-se o que nela entra; às vezes percebe-se o que dela sai. Não se sabe bem o que nela se passa” (p. 29). 
Há, portanto, dificuldades relacionadas à insuficiência das teorias disponíveis, às formas de representação e de linguagem, à "literaturização" (SANTOS, I994) e também às evidências empíricas (HARVEY, I989).

A questão da representação, da linguagem, e da prática está em Santos (I994), quando este autor nos fala do lugar como a sede de uma possível resistência da sociedade civil, em sua excelente reflexão sobre o território usado. Assim ele se expressa:

[...] nada impede que aprendamos as formas de estender esta resistência às escalas mais altas. Para isto, é indispensável insistir na necessidade de conhecimento sistemático da realidade, mediante o tratamento analítico desse seu aspecto fundamental que é o território (o território usado, o uso do território). Antes, é essencial rever a realidade de dentro, isto é, interrogar a sua própria constituição neste momento histórico. O discurso e a metáfora, isto é, a literaturização do conhecimento, podem vir depois, devem vir depois. (SANTOS, I994, p.I9)

Assim como Lefebvre, Santos, por um lado, enfatiza a importância da prática, nesse caso reativa - "uma possível resistência da sociedade civil” - uma coesão horizontal contra as forças verticalizadas e singularizadas do mercado. Por outro lado, no entanto, este autor insiste na indispensabilidade de "conhecimento sistemático da realidade", o que Lefebvre afirma ser quase uma impossibilidade quando se considera que, no processo de se pensar a possibilidade de mudança social, não se trata mais de entender somente a realidade atual, apesar de necessário, mas de ir além, para desvendar o que se passa dentro da "caixa preta". No entanto, o pensamento desses dois autores se aproxima ao refletirem sobre as dificuldades de representação do real (Lefebvre) e a necessidade de "rever a realidade de dentro" antes da literaturização do conhecimento (Santos). Em síntese, ambos os autores estão falando sobre as dificuldades de aproximação com o real.

Por fim, vale a pena atentar para outra questão, posta por Harvey, relacionada à problemática aqui discutida. Trata-se de uma dificuldade a mais para as tentativas de aproximação com o real. Harvey (I989, p. 2), refletindo sobre a formação de conceitos e a construção de teorias como sendo um dos aspectos vitais da atividade humana, identifica problemas na busca de alguma metateoria do processo urbano. Por metateoria o autor está se referindo a "um framework teórico que tem o potencial de colocar todas as visões parciais juntas não somente como uma visão composta, mas 
como um mapa cognitivo que mostre como Lefebvre nos coloca cada visão pode ela mesma ser explicada por e integrada em uma grande concepção sobre o que é a cidade como um todo, o que é o processo urbano em geral". Ou seja, Harvey está se referindo ao urbano industrial e não ao campo cego de Lefebvre a que vimos nos referindo acidiante de um dilema: as 'capas verbais' que são capazes de nos revelar o espaço industrial são insuficientes para ma. Ao colocar tais questões, aquele autor faz sua opção pela metateoria marxiana por considerá-la como "o mais poderoso de todos os desvendar o que se encontra dentro da esquemas de explicação disponíveis” (HARVEY, i989, p. 3). 'CaiXa preta’

Isso posto, o autor nos leva também a refletir sobre as possibilidades de aproximação com o real, quando ele vê dificuldades na questão da empiria. "As representações particulares que nós chamamos 'fatos' ou 'dados' não são independentes das teorias que os informam e às quais eles podem ser aplicados. A escolha está entre os diferentes modos de abordagem deste problema universal" (Idem, p. 6-7, destaques no original). Em continuação Harvey nos alerta para os dilemas relacionados ao que podemos chamar de evidências empíricas, fatos e dados:

O que constitui prova de uma meta-teoria como a de Marx não é uma questão simples. [...] Prova não pode ser reduzida (como muitos críticos da meta-teoria Marxiana parecem propor) a um simples procedimento de teste contra um supostamente novo conjunto de dados factuais. A imposição de padrões positivistas de prova sobre a teoria Marxiana significa aceitar positivismo e não Marxismo como base de trabalho. (Idem, p. I3)

Portanto, Harvey nos coloca diante de mais uma dificuldade quando a questão é a aproximação com o real. Se este "real" não é de fato real, e é permeado de ideologias, utopias, desejos e simbolismos, dependendo, entre outras coisas, da condição de classe social e da cultura, seriam inócuos os esforços de aproximação com a realidade? A construção de possiblidades de mudança social e de emancipação poderia ser realizada por meio da aproximação direta entre o pensamento filosófico, a filosofia política e a prática? De qual prática estamos falando? Refletir sobre a possibilidade da prática, identificar e propor possíveis práticas e/ou assessorar 
movimentos sociais autônomos, como se faz no meio intelectual-acadêmico (extensão universitária) pode ser identificado como práticas que contribuam para o processo emancipatório? Como fazer isso diante das dificuldades acima problematizadas de aproximação com o real? Aí entra uma questão importante a que nos referimos acima: a utopia derivada do pensamento filosófico poderia orientar não apenas propostas concretas, mas também ações, por exemplo, dentro de um processo heterônomo, e. g., de planejamento urbano?

Pensando inicialmente nas ações autônomas, vale a pena reproduzir trechos de uma entrevista com Adorno, em ig69, no mesmo ano em que morreu. A entrevista (ADORNO, 2003) girou em torno da relação entre teoria e prática em um momento em que um posicionamento diante dos acontecimentos por parte deste filósofo foi cobrado por seus alunos engajados nos movimentos que tiveram início em maio de iو68 na Europa urbana. A entrevista representa sem dúvida uma importante síntese do pensamento do filósofo sobre essa relação. Perguntado como ele queria modificar a totalidade social sem ações isoladas (como as que estavam ocorrendo na Europa), Adorno responde que "verificou-se inúmeras vezes na história que precisamente obras que perseguiam propósitos puramente teóricos tenham modificado a consciência e, com isso, também a realidade social" (ADORNO, 2003, p. 6). Outra pergunta e resposta em especial deixa bem claro o pensamento de Adorno sobre a questão.

Entrevistador: "Seria então a virtude da filosofia encarar de frente (sic) o negativo, mas não invertê-lo?"

Adorno: "A filosofia não pode, por si só, recomendar medidas ou mudanças imediatas. Ela muda precisamente à medida que permanece teoria. Penso que seria o caso de perguntar se, quando alguém pensa e escreve as coisas como eu faço, se isso não é também uma forma de opor-se. Não será também a teoria uma forma de prática?” (ADORNO, 2003, p. 7) 
5. Atualmente tem havido uma tentativa de elevar este número para 30.

6. O convite foi feito por um setor da Secretaria de Estado de Desenvolvimento Regional e Urbano, que já vinha contando com o trabalho de setores da Universidade em pesquisas sobre a questão metropolitana. quando ocorreu a eleição de representantes da sociedade civil no Conselho Deliberativo, o qual é parte de um novo arranjo institucional então recém-aprovado para a RMBH. Isso significaria que as organizações da sociedade civil, formais ou informais, autônomas ou heterônomas, poderiam de fato inserir-se em formas participativas de planejamento e de gestão metropolitanos. Esse retorno, que significou uma oportunidade para instituir uma prática de aprendizado e de controle social sobre os processos socioespaciais metropolitanos, inclui desde a elaboração do PDDI, passando pela possibilidade de constituição de um processo de planejamento e chegando à participação efetiva na gestão metropolitana. Houve, no momento da Conferência, uma ampla mobilização da sociedade civil, que manifestou insatisfação com o pequeno espaço ocupado por seus delegados no Conselho Deliberativo: dois em um total de i6 conselheiros. Como resultado da mobilização, foi proposto e criado um Colegiado Metropolitano da Sociedade Civil, informal e fora do arranjo legal, mas que tem se mostrado muito efetivo. Inicialmente composto de 20 membros $^{5}$ representantes de universidades, ONGs, associações profissionais (engenheiros, arquitetos, entre outros), sindicatos de trabalhadores, organizações populares etc., o Colegiado agrega interesses relacionados a um amplo leque de questões metropolitanas de caráter político, econômico, social, ambiental e cultural. Além de dar suporte técnico e político aos dois representantes da sociedade civil no Conselho Deliberativo, esse Colegiado tem atuado como um importante fórum de discussão e proposição de ideias tanto para novas pesquisas e análises de temas metropolitanos diversos, quanto para o processo integrado de planejamento e de gestão. Este Colegiado foi responsável pela criação de um termo de referência para a elaboração do PDDI, o qual foi aprovado pelo Conselho Deliberativo.

O próximo passo foi o convite feito pelo governo estadual ${ }^{6}$ à UFMG para elaborar o Plano. Pode-se dizer que essas ações, de vários agentes da sociedade civil, constituem práticas autônomas promissoras para compor um processo participativo de planejamento, de gestão e de controle social em escala metropolitana. Além disso, o PDDI incorpora inovações significativas em termos de princípios, metodologia e prática de planejamento em um novo contexto político e social, diferente daquele das primeiras experiências de planejamento metropolitano tecnocrático, experimentadas nos anos I970/I980. Uma síntese disso está expressa nesta passagem da introdução do texto Plano: 
[...] a abordagem crítica supera o sentido analítico e funcional de um planejamento reformista, sem desqualificá-lo, mas limitando-o ao seu caráter operacional e imediato e indo além, com o objetivo de pensar a totalidade em transformação e buscar construir processos voltados para a transformação social, econômica e ambiental, buscando soluções contemporâneas para regulação, decisões de investimentos, formas de organização social que privilegiem as diversidades e a construção de processos sociais emancipatórios. (UFMG/PUC-MINAS/UEMG, 20II, p. 5)

Nessa passagem, pode-se observar que se acredita na possibilidade de a reflexão e a análise críticas serem capazes de construir uma aproximação direta com a prática. Ainda em relação a essa passagem, poder-se-ia dizer que um importante aspecto dos princípios e da orientação metodológica no processo de elaboração do PDDI não foi, na prática, o de esquecer os princípios de um planejamento reformista, mas a sua transcendência. Ou seja, não somente "limitando-o ao seu caráter operacional e imediato", mas também acreditando nos princípios da modernidade, especialmente a busca da igualdade, e na possibilidade de um Estado democrático adotar o planejamento como um processo contínuo e participativo visando “à construção de processos sociais emancipatórios”. Em todo o processo de elaboração dos estudos do Plano, alguns princípios, que se relacionam com o papel da Universidade, foram constantemente observados e praticados: associação entre o saber técnico-científico e o saber que emana da vida quotidiana; e o sentido contemporâneo do planejamento: mudando de reforma social para mobilização e aprendizado social (Idem, 20II).

Outro aspecto metodológico que merece destaque refere-se à adoção do conceito de totalidade em vez da ideia de compreensividade. Tal mudança requer, em termos metodológicos, o movimento de uma abordagem multidisciplinar, adotada nas primeiras experiências de planejamento urbano e metropolitano no Brasil, para uma visão transdisciplinar (COSTA, 2008). Na prática do planejamento, isso significou que as análises e proposições do PDDI seguiram uma metodologia inovadora que superou a abordagem setorial e multidisciplinar em favor de uma visão transdisciplinar por meio do que se denominou "eixos temáticos integrados" da totalidade social metropolitana - acessibilidade, sustentabilidade, seguridade e urbanidade.7 Todas as propostas do plano dentro desses eixos estão também dentro de duas dimensões integradoras do PDDI: territorialidade e institucionalidade.
7. Por ser muito extensa, deixo de apresentar aqui a construção conceitual e o conteúdo desta proposta de análise da totalidade socioespacial metropolitana, que permitiu, de fato, uma aproximação entre as reflexões teóricas e a realidade. A construção da proposta pode ser acessada em <http:// www.metropolitana.mg.gov. $\mathrm{br} /$ documents/pddi/relatorio-final-cedeplar/pddi-rmbhrelatorio-final-volume-1.pdfs. 
8. O processo de elaboração do Plano, que durou um ano, envolveu em torno de 180 professores, estudantes e pessoal técnico-administrativo da Universidade. Um total de aproximadamente duas mil participações foi computado ao longo do processo de elaboração do Plano.
Com isso, essa metodologia, que foi sendo construída na prática participativa e “incorporação do saber da vida quotidiana” no processo de reflexões para a análise e o planejamento, significou avanços efetivos na aproximação com a realidade (totalidade socioespacial). Além disso, a metodologia mostrou ter sucesso em pelo menos outros dois aspectos. Primeiro, ela foi importante, conforme dito acima, como uma forma de quebrar a abordagem setorial, considerada inadequada para analisar a complexa totalidade socioespacial metropolitana. Assim, por exemplo, habitação diz Habitação diz respeito não respeito a todos os quatro eixos. apenas a acessibilidade, Ou seja, habitação diz respeimas tanbén a também a sustentabilidade, seguridade e urbanidade. sustentabilidade, Desenvolvimento econômico é outro exemplo de seguridade e urbanidade uma questão que foi considerada em mais de um dos quatro eixos, apesar de ter sido desenvolvida no eixo sustentabilidade, o que, por si só, já significou um grande avanço em relação à difícil ideia de situar a análise econômica em um contexto inter e transdisciplinar. Um segundo aspecto muito positivo da metodologia diz respeito aos processos de participação e de aprendizado social. A ideia de quatro eixos temáticos integradores foi facilmente entendida, assimilada e adotada por aqueles que compareceram nas oficinas do processo participativo. ${ }^{8}$ Os problemas imediatos, associados ao quotidiano dos diversos grupos sociais, passaram a ser pensados e debatidos, com vistas à busca de soluções, com uma visão mais próxima da totalidade socioespacial metropolitana.

Participação tem, portanto, significado um promissor embrião de prática e de controle político e social no planejamento e gestão metropolitanos na RMBH. O processo participativo na elaboração do plano deu origem a outra organização da sociedade civil além do Colegiado Metropolitano da Sociedade Civil: Frente Pela Cidadania Metropolitana. Trata-se de uma espécie de rede social que tem como objetivo, como o próprio nome sugere, a consolidação de uma cidadania metropolitana, e que tem exercido importante papel de mobilização e controle social em torno da problemática metropolitana. Acredita-se que tais processos se constituem em meios que irão contribuir para consolidar um tipo de "identidade de projeto" que emerge, nas palavras de Castells, 
“quando atores sociais, com base em materiais culturais que estão disponíveis para eles, constroem uma nova identidade que redefine suas posições na sociedade e, fazendo isto, estão buscando a transformação de toda a estrutura social” (CASTELLS, I997, p. 8).

Enfim, estamos falando de "o direito à cidade" e da possibilidade de realização da sociedade urbana. Apesar de os textos de Lefebvre (I999) se constituírem em reflexões essencialmente teóricas - e, por isso mesmo, com a necessária abstração -, em torno da ideia de "revolução urbana”, o autor não nega a importância da "planificação" como se observa em uma de suas teses expostas em $O$ direito à cidade:

A realização da sociedade urbana exige a planificação orientada para as necessidades sociais, as necessidades da sociedade urbana. Ela necessita de uma ciência da cidade (das relações e correlações na vida urbana). Necessárias, estas condições não bastam. Uma força social e política capaz de operar esses meios (que não são mais do que meios) é igualmente indispensável. (LEFEBVRE, 2008, p. I38)

Pode-se completar esta passagem do autor repetindo suas palavras anteriormente citadas neste ensaio: “Um movimento do pensamento em direção a um certo concreto e talvez para o concreto se esboça e se precisa. Esse movimento, caso se confirme, conduzirá a uma prática, a prática urbana, apreendida ou re-apreendida” (LEFEBVRE, I999, p. I8, destaques no original).

Voltando ao caso da RMBH, pode-se dizer que há a possibilidade de estar ocorrendo a formação e o espraiamento de embriões dessas práticas urbanas, as quais, nos termos de Harvey (2009), citando Gramsci, podem ser interpretadas como parte de um "otimismo da vontade" (optimism of the will) de movimentos sociais. Em contrapartida, este mesmo autor chama a atenção para o fato de que "A inabilidade para encontrar um 'otimismo do intelecto' com o qual construir alternativas, tem se tornado no momento uma das mais sérias barreiras a políticas progressistas" (HARVEY, 2009, p. 32).

Em conclusão, acredito que se pode dizer que o envolvimento intelectual (do meio acadêmico) com planejamento e práticas sociais urbanas, como tem se observado no caso da UFMG em relação à RMBH, pode ser traduzido como uma tentativa de quebrar tais barreiras e de buscar a aproximação entre a teoria, o real e a prática urbana de maneira a contribuir para a proposição (e efetividade) de políticas progressistas e 
de formas de gestão urbanas/metropolitanas democráticas. Com isto, está-se passando de utopias e virtualidades, essenciais para a construção de teorias emancipatórias, para a prática social ou para a identificação de formas para "pôr alternativas em prática”, nos termos de Harvey (2009, p. 240). Conceitos caros ao pensamento lefebvriano, como o direito à cidade, totalidade social, sociedade urbana e espaço diferencial, estavam presentes em todos os momentos da prática de planejamento aqui descrita, sem que, contudo, isto tenha significado corromper ou banalizar o potencial teórico que tais conceitos têm no processo de pensar a construção de possibilidades emancipatórias. Apesar de boa parte das várias perguntas colocadas para reflexão não ter sido devidamente problematizada, espera-se que o conteúdo deste ensaio contribua para se pensar a possibilidade de realização da sociedade urbana e, consequentemente, de aproximação com a também possível emancipação social, política e cultural.

\section{Referências}

ADORNO, T. A astúcia da dialética. Caderno Mais, p. 4-7, 3I ago. 2003. Entrevista concedida em I979, publicada na Folha de S.Paulo.

BECKER, B. Modernidade e gestão do território no Brasil: da integração nacional à integração competitiva. Espaço e Debates. São Paulo, ano XI, v. 32, p. 47-56, I99I.

CARDOSO, A.L. Reforma urbana e planos diretores: avaliação da experiência recente. Cadernos IPPUR, Rio de Janeiro, ano XI, n. I e 2, p. 79-III, I997.

CASTELLS, M. The power of identity. Oxford: Blackwell Publishers, I997.

COSTA, G. M. Prática e ensino em planejamento (urbano) no Brasil: da "velha" compreensividade multidisciplinar à abordagem transdisciplinar. In: COSTA, G. M.; MENDONÇA, J. G. (Org.). Planejamento urbano no Brasil: trajetória, avanços e perspectivas. Belo Horizonte: C/Arte/CNPq, 2008. p. 66-78.

COSTA, G. M. As possibilidades do planejamento e da gestão participativa na escala metropolitana como um meio para a mudança social: o caso da Região Metropolitana de Belo Horizonte (RMBH). In: SEMINÁRIO SOBRE A ECONOMIA MINEIRA, I5., 2OI2, Diamantina. Anais..., Belo Horizonte: CEDEPLAR, 20I2. v. I, p. I-I6.

DAVIDOVICH, F. A "volta da metrópole" no Brasil: referências para a gestão territorial. In: RIBEIRO, L. C. Q. (Org.). Metrópoles: entre a coesão e a fragmentação, a cooperação e o conflito. Rio de Janeiro: Fase/Observatório das Metrópoles/Fundação Perseu Abramo, 2004. p. 197-229. 
GOTTDIENER, M. A produção social do espaço urbano. São Paulo: EDUSP, I993.

HARVEY, D. The urban experience. Baltimore: The Johns Hopkins University Press, I989.

HARVEY, D. Espaços de esperança. São Paulo: Edições Loyola, 2009.

KOFMAN, E.; LEBAS, E. (Ed.). Writings on cities: Henri Lefebvre. Cambridge: Blackwell, I996.

LEFEBVRE, H. Space: social product and use value. In: FREIBERG, J. (Ed.). Critical sociology:

European perspective. New York: Irvington Publishers, I979. p. 285-295.

LEFEBVRE, H. Entrevista: conversa com Henri Lefebvre. Trad. Manuel Rolando Berríos. Espaço e Debates, n. 30, p. 6I-69, I990.

LEFEBVRE, H. The production of space. Oxford: Blackwell, I993.

LEFEBVRE, H. A revolução urbana. Belo Horizonte: Ed. UFMG, I999.

LEFEBVRE, H. O direito à cidade. São Paulo: Centauro Editora, 2008.

MARICATO, E. Reforma urbana: limites e possibilidades - uma trajetória incompleta. In:

RIBEIRO, L. C. Q.; SANTOS JÚNIOR, O. (Org.) Globalização, fragmentação e reforma urbana: o futuro das cidades brasileiras na crise. Rio de Janeiro: Civilização Brasileira, I994. p. 309-325.

MARICATO, E. Brasil 2000: qual planejamento urbano? Cadernos IPPUR, Rio de Janeiro, ano XI, n. I e 2, p. II3-I30, jan./dez. I997.

SANTOS, M. O retorno do território. In: SANTOS, M. et al. (Org.). Território: globalização e fragmentação. São Paulo: HUCITEC/ANPUR, I994· p. 15-20.

SOUZA, M. L. Mudar a cidade: uma introdução crítica ao planejamento e à gestão urbanos. Rio de Janeiro: Bertrand Brasil, 2003.

UFMG/PUC-MINAS/UEMG. Plano Diretor de Desenvolvimento Integrado: Região Metropolitana de Belo Horizonte, 2oII, v. I. Disponível em: <http://www.metropolitana.mg.gov.br/documents/ pddi/relatorio-final-cedeplar/pddi-rmbh-relatorio-final-volume-I.pdf>. Acesso em: 20 mar. 2013. 